Article

\title{
Exploring Target Genes Involved in the Effect of Quercetin on the Response to Oxidative Stress in Caenorhabditis elegans
}

\author{
Begoña Ayuda-Durán ${ }^{1}$, Susana González-Manzano ${ }^{1}{ }^{\mathbb{D}}$, Antonio Miranda-Vizuete ${ }^{2}{ }^{\mathbb{D}}$, \\ Eva Sánchez-Hernández ${ }^{1}$, Marta R. Romero ${ }^{3}$, Montserrat Dueñas ${ }^{1}{ }^{(D)}$, \\ Celestino Santos-Buelga ${ }^{1, *(\mathbb{D})}$ and Ana M. González-Paramás ${ }^{1}$ (D) \\ 1 Grupo de Investigación en Polifenoles, Universidad de Salamanca, Campus Miguel de Unamuno, \\ 37007 Salamanca, Spain; bego_ayuda@usal.es (B.A.-D.); susanagm@usal.es (S.G.-M.); \\ evasanher@usal.es (E.S.-H.); mduenas@usal.es (M.D.); paramas@usal.es (A.M.G.-P.) \\ 2 Instituto de Biomedicina de Sevilla, Hospital Universitario Virgen del Rocío/CSIC/Universidad de Sevilla, \\ 41013 Sevilla, Spain; amiranda-ibis@us.es \\ 3 Center for the Study of Liver and Gastrointestinal Diseases (CIBERehd), Experimental Hepatology and Drug \\ Targeting (HEVEFARM), Universidad de Salamanca, Institute for Biomedical Research of \\ Salamanca (IBSAL), 37007 Salamanca, Spain; marta.rodriguez@usal.es \\ * Correspondence: csb@usal.es
}

Received: 15 November 2019; Accepted: 20 November 2019; Published: 25 November 2019

\begin{abstract}
Quercetin is one the most abundant flavonoids in the human diet. Although it is well known that quercetin exhibits a range of biological activities, the mechanisms behind these activities remain unresolved. The aim of this work is to progress in the knowledge of the molecular mechanisms involved in the biological effects of quercetin using Caenorhabditis elegans as a model organism. With this aim, the nematode has been used to explore the ability of this flavonoid to modulate the insulin/insulin-like growth factor 1(IGF-1) signaling pathway (IIS) and the expression of some genes related to stress response. Different methodological approaches have been used, i.e., assays in knockout mutant worms, gene expression assessment by RT-qPCR, and C. elegans transgenic strains expressing green fluorescent protein (GFP) reporters. The results showed that the improvement of the oxidative stress resistance of $C$. elegans induced by quercetin could be explained, at least in part, by the modulation of the insulin signaling pathway, involving genes age-1, akt-1, akt-2, daf-18, sgk-1, daf-2, and $s k n-1$. However, this effect could be independent of the transcription factors DAF-16 and HSF-1 that regulate this pathway. Moreover, quercetin was also able to increase expression of $h s p-16.2$ in aged worms. This observation could be of particular interest to explain the effects of enhanced lifespan and greater resistance to stress induced by quercetin in C. elegans, since the expression of many heat shock proteins diminishes in aging worms.
\end{abstract}

Keywords: quercetin; IIS pathway; C. elegans; oxidative stress

\section{Introduction}

Quercetin $(\mathrm{Q})$ is the most abundant flavonol in the human diet, being present in a wide variety of plant-derived foods, such as nuts, grapes, onions, broccoli, apples, or black tea. Dietary quercetin consumption has been associated to different health benefits, including antioxidant and anti-inflammatory effects and protection against aging-related diseases, such as cardiovascular pathologies, cancer, and neurodegenerative disorders [1-3]. Classically, these actions have been explained, at least in part, by its antioxidant and free-radical scavenging properties, as demonstrated in in vitro studies $[4,5]$, although the actual mechanisms through which quercetin and other flavonoids 
exert their in vivo effects remain unresolved. Understanding the molecular mechanisms by which $\mathrm{Q}$ can exert its biological activity is important in order to develop strategies to modulate the physiological changes associated with aging that lead to chronic diseases. Although studies with quercetin and other flavonoids using in vivo models have increased in recent years, most of the knowledge on their biological activity still derives from in vitro or ex vivo findings, while assays that consider complex interactions of various processes, such as absorption, metabolism, and interaction with organs and tissues are more limited [6].

Some important molecular pathways in complex organisms can be explored using the model organism Caenorhabditis elegans. There is a high degree of homology between C. elegans and human genes involved in different processes, such as aging, apoptosis, cell signaling, cell polarity, metabolism, or cell cycle, which are conserved between mammals and the nematode [7]. In fact, C. elegans offers promising possibilities to study mechanisms of action and effects of secondary compounds of foods and plants, due to its simplicity of handling, conservation of metabolic pathways, and the possibility of manipulating cell signaling routes by biotechnological methods. In addition, it is not pathogenic, and no ethical boundaries exist to its experimental usage.

Different studies have evaluated the biological effects of quercetin and related compounds in C. elegans. In a previous work, we have shown that growing C. elegans in the presence of $200 \mu \mathrm{M}$ of $\mathrm{Q}$ or its $3^{\prime}$ - and 4'-O-methylated metabolites significantly prolonged the lifespan and increased the resistance against thermal- and juglone-induced oxidative stress [8]. Further support was obtained by checking the oxidation status of proteins in the nematode, which was greatly reduced [8]. Similar observations were also made by other authors [9-13]. Treatment with $Q$ was also seen to lead to a reduction in the intracellular levels of reactive oxygen species (ROS), either in nematodes subjected to or not subjected to stress [11,13-15]. In general, these studies show that $Q$ possesses a relevant biological activity in an in vivo system, which results in greater protection against oxidative processes. Regarding worm lifespan, an extension has been found in worms grown in the presence of concentrations of $Q$ between 70 and $200 \mu \mathrm{M}$, while no lifespan extension was observed for $\mathrm{Q}$ concentrations outside that range. On the contrary, a hormetic response of the worm to this phytochemical has been demonstrated, so that the increase in the concentration of quercetin above certain levels results in decreased survival [16]. Nevertheless, the molecular mechanisms through which these effects are produced are still unclear, and different explanations, sometimes apparently contradictory, have been offered by distinct authors [9-14].

The response to oxidative stress in C. elegans is regulated through several pathways, including those of insulin/IGF-1 (IIS), c-Jun N-terminal kinases (JNK), and the signaling p38 MAPK (mitogen-activated protein kinases) pathway [17-19]. The IIS pathway (Figure 1) controls many important biological processes, including development, reproduction, metabolism, somatic maintenance, and stress resistance [20]. Insulin-like peptides binding to DAF-2, the orthologue of the insulin/IGF-1 receptor in C. elegans [21], activate its tyrosine kinase activity. This activation triggers a cascade of phosphorylation events through different kinases (AGE-1/PI3k, PDK-1, AKT-1/2, and SGK-1) that promote the phosphorylation-dependent cytoplasmic sequestration of the factors DAF-16/FoxO, HSF-1, and SKN-1/Nrf, preventing their transcriptional activity [22]. On the other hand, loss of insulin signaling in C. elegans results in several cytoprotective phenotypes resistant to both thermal and oxidative stress and also increases pathogen resistance and lifespan [23]. Flavonoids could influence cellular systems changing the expression of different genes through the modulation of distinct transcription factors, acting simultaneously on various signaling pathways, including the IIS pathway [24]. 


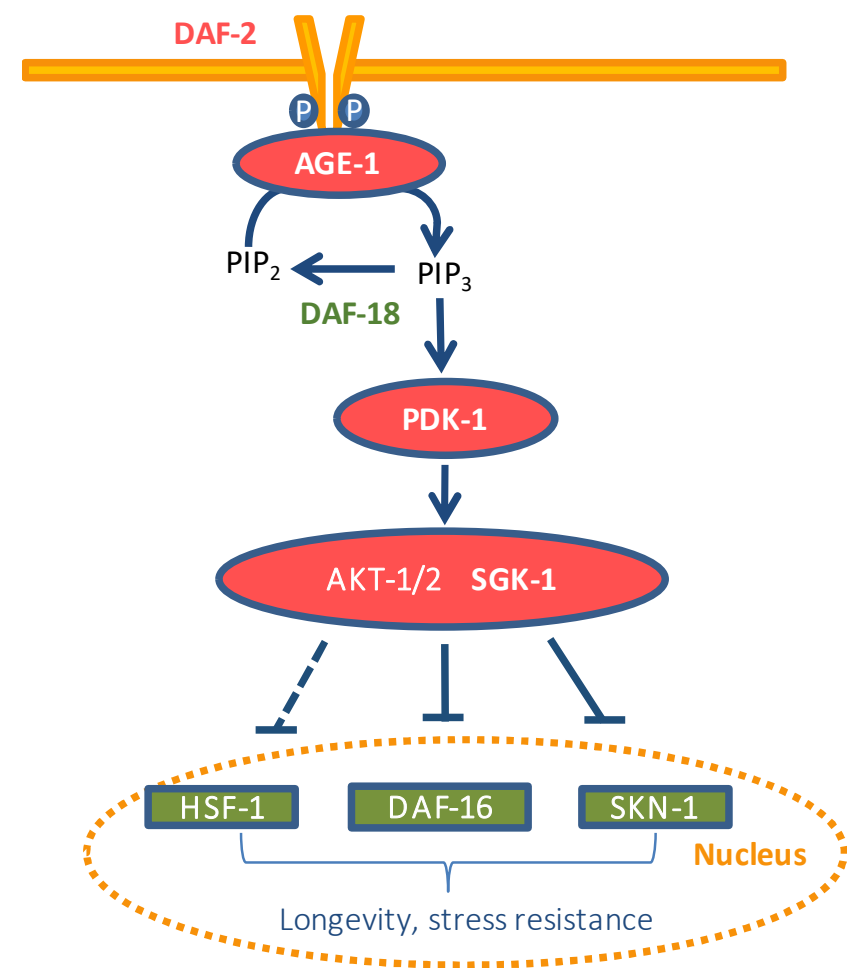

Figure 1. Scheme of the insulin/IGF-1 signaling pathway (IIS) in C. elegans. The components of the pathway that promote IIS are colored red and those that either antagonize IIS or are antagonized by IIS are colored green.

In order to contribute to elucidate the mechanisms involved in the effects of flavonoids, in this work, the ability of quercetin to modulate the insulin/IGF-1 signaling pathway (IIS) has been explored. Specifically, the influence on the resistance to thermally-induced oxidative stress has been assessed using C. elegans strains with loss-of-function mutations in genes of the IIS pathway (i.e., daf-2, age-1, daf-16, akt-1, akt-2; sgk-1, hsf-1, skn-1, and daf-18). Additionally, the ability of Q to modify the expression of some genes related to stress, namely daf-16, hsf-1, skn-1, hsp-16.2, hsp-70, sod-3, and gst-4, has also been determined by RT-qPCR or using the GFP fluorescent reporter in C. elegans transgenic strains.

\section{Materials and Methods}

\subsection{Standards and Reagents}

Quercetin (Q), ampicillin sodium salt, nistatine, agar, yeast extract, fluorodeoxyuridine (FUdR), phosphate-buffered saline (PBS), cholesterol, and 2-mercaptoethanol, were purchased from Sigma-Aldrich (Madrid, Spain). Dimethyl sulfoxide (DMSO) was obtained from Panreac (Barcelona, Spain). SYBR ${ }^{\circledR}$ SelectMaster Mix and high-capacity cDNA reverse transcription kit were from Applied Biosystems (Carlsbad, CA, USA), and the Illustra ${ }^{\mathrm{TM}}$ RNAspin mini isolation kit was from GE Healthcare (Buckinghamshare, UK).

\subsection{Strains and Maintenance Conditions}

The wild-type strain N2 and the mutant strains VC475, hsp-16.2(gk249) V; CB1270, daf-2 (e1370) III; TJ1052, age-1(hx546) II; CF1038, daf-16(mu86) I; CB1375, daf-18(e1375) IV; BQ1, akt-1(mg306) V; KQ1323, akt-2(tm812) sgk-1(ft15) X; PS3551, hsf-1(sy441) I; EU1, skn-1(zu67) IV/nT1(unc-?(n754)let-?) (IV;V); CF1553, muls84 ((Psod-3::gfp)); TJ356, zIs356 (Pdaf-16::daf-16::gfp; rol-6 (su1006)) IV; CL2166, dvIs19 ((Pgst-4::gfp::NLS; rol-6 (su1006)) III; AM446, rmIs223 (Phsp70::gfp; rol-6(su1006)); CL2070, dvIs70 (Phsp-16.2::gfp; rol-6 (su1006)), as well as the E. coli OP50 bacterial strain, were obtained from 
the Caenorhabditis Genetics Center (CGC) at the University of Minnesota (Minneapolis, MN, USA). Worms were routinely propagated at $20^{\circ} \mathrm{C}$ on nematode growth medium (NGM) plates with E. coli OP50 as a food source.

Synchronization of worm cultures was achieved by treating gravid hermaphrodites with bleach: $5 \mathrm{~N} \mathrm{NaOH}(2: 1)$. Eggs are resistant whereas worms are dissolved in the bleach solution. The suspension was shaken with a vortex mixer during $1 \mathrm{~min}$ and kept for a further minute on rest, this process was repeated five times. The suspension was centrifuged $(2 \mathrm{~min}, 9500 \mathrm{~g})$. The pellet containing the eggs was washed six times with an equal volume of buffer $\mathrm{M} 9\left(3 \mathrm{~g} \mathrm{KH}_{2} \mathrm{PO}_{4}, 6 \mathrm{~g} \mathrm{Na} 2 \mathrm{HPO}_{4}, 5 \mathrm{~g} \mathrm{NaCl}, 1 \mathrm{~mL}\right.$ $1 \mathrm{M} \mathrm{MgSO}_{4}, \mathrm{H}_{2} \mathrm{O}$ to $1 \mathrm{~L}$ ). Quercetin solution $(200 \mathrm{mM})$ in DMSO was added to the nematode growth medium during its preparation to get a $200 \mu \mathrm{M}$ final concentration on the plates. Control plates were also prepared without the flavonoid but containing the same volume of DMSO $(0.1 \%$ DMSO, $v / v)$. Around 100 to $300 \mu \mathrm{L}$ of the M9 with eggs (depending on eggs Øconcentration) were transferred and incubated on NGM agar plates with or without $Q$. When the worms reached the L4 stage, they were transferred to new plates with or without $Q$ but also containing FUdR at a concentration of 150 $\mu \mathrm{M}$ to prevent reproduction and progeny overgrowth. The worms were transferred every 2 days to fresh plates with FUdR for the different treatments (with or without Q) until they reached the day of the assay.

\subsection{Stress Assays}

Oxidative stress in worms was induced by subjecting the animals to $35^{\circ} \mathrm{C}$ heat-shock treatment. Worms were incubated at $20^{\circ} \mathrm{C}$ on NGM-E. coli OP50 plates with or without $\mathrm{Q}$ until days 2 and 9 of adulthood. Then they were transferred with a platinum wire to agar plates $\varnothing 35 \mathrm{~mm}, 20$ worms per plate) and switched to $35^{\circ} \mathrm{C}$ for 4,6 , or $8 \mathrm{~h}$. The time was decided depending on the thermotolerance of the specific worm strain used in the assay, which was previously checked. After that time, dead and alive nematodes were counted. In the studies involving the use of worm mutants, in addition to the mutant control, a parallel control using N2 wild-type (WT) worms was also included. For the assays, ten plates were used per treatment containing 20 worms per plate, resulting in a total of 200 worms, although a small percentage of worms was usually lost in the score. Only in the case of the skn-1 mutant (EU1) were 300 worms ( 20 worms per plate/15 plates) used. According to the information supplied by the CGC, the work with this mutant required special considerations, as only the homozygote worms with WT appearance are considered for the assay, while the uncoordinated heterozygote worms are only employed to maintain the lineage. To have reproducible results in the heat shock assays, that is, to have the smallest possible temperature oscillations, some precautions were followed, in agreement with the guidelines stated in the reference paper [25]. During assays, the door of the incubator was only opened when the survival rate had to be measured. The plates were not stacked inside the incubator, they were placed in a row on the same shelf of the incubator, leaving enough space between them for the air to circulate properly. The temperature was controlled with the incubator's own thermostat and with an external thermostat with sensors inside the incubator to monitor possible temperature oscillations.

\section{4. $R T-q P C R$ Assays}

Adult worms of the N2 C. elegans strain were treated with or without $200 \mu \mathrm{M}$ of $\mathrm{Q}$ for 4 days. The worms were collected with M9 buffer, centrifuged at 10,000 $\mathrm{g}$ for $1 \mathrm{~min}$, and the pellet was dissolved in $300 \mu \mathrm{L}$ of M9, to which $3.5 \mu \mathrm{L}$ of 2-mercaptoethanol was added. Total RNA was extracted using the RNAspin Mini RNA Isolation Kit (GE Healthcare). In order to maximize cell breakage, in the first stage of the extraction, 10 stainless-steel beads $(2 \mathrm{~mm})$ were added. The mixture was vortex shaken vigorously and further homogenized in a Thermo Savant FastPrep 120 Cell Disrupter System, with a speed of $5.5 \mathrm{~m} / \mathrm{s}$ and run time duration of $10 \mathrm{~s}$, five times. cDNA was produced with high-capacity cDNA reverse transcription kit (Applied Biosystems) using $2 \mu \mathrm{g}$ of total RNA per reaction. The expression of mRNA was assessed by quantitative real-time PCR, using SYBR green as 
the detection method. The gene expression data were analyzed using the comparative $2^{-\Delta \Delta \mathrm{Ct}}$ method, with act-1 as the normalizer [26]. Nine independent experiments were performed. Act-1 was used as a normalizer both in the assays carried out in non-stressed and stressed worms. The information related to gene-specific primers used in this work can be found in the Supplementary Table S1.

\subsection{Fluorescence Quantification and Visualization}

Synchronized L1 larvae expressing an inducible green fluorescent protein (GFP) reporter for $g s t-4, h s p-16.2, h s p-70$, sod-3, and daf-16 genes were grown on NMG plates in the presence or absence of $Q$ until the day of the assay, when they were subjected to or not subjected to thermally-induced oxidative stress $\left(35^{\circ} \mathrm{C}, 1 \mathrm{~h}\right.$ ). The precise day of assay was defined when a higher intensity of the fluorescence was observed after carrying out a screening with the different strains throughout the life of the worm, namely, day 3 in gst-4 and day 5 in $h s p-70$. For the remaining strains, as no clear increase in the fluorescence was observed, the assessment was made in young (day 2 of adulthood) and older adult worms (day 9 of adulthood). In the cases of $h s p-16.2$ and $h s p$-70 reporter strains, after thermal stress, the worms were allowed to recover at $20{ }^{\circ} \mathrm{C}$ for 2 or $3 \mathrm{~h}$ respectively, before pictures were taken. The expression of $g s t-4, h s p-16.2, h s p-70$, and sod-3 was measured by quantifying the fluorescence of the GFP reporter. To analyze the subcellular localization of the DAF-16::GFP reporter, worms were classified as diffuse cytoplasmic, intermediate cytoplasmic/nuclear, and strong nuclear translocation. Approximately 35 randomly selected worms for each experiment were mounted in a $5 \mu \mathrm{L}$ drop of $10 \mathrm{mM}$ levamisole (except for DAF-16::GFP in 2\% sodium azide) on a $3 \%$ agarose pad covered with a coverslip. All fluorescence determinations were done in an Olympus BX61 fluorescence microscope equipped with a filter set (excitation $470 \pm 20 \mathrm{mn}$, emission $500 \pm 20 \mathrm{~nm}$ ) and a DP72 digital camera coupled to CellSens Software for image acquisition and analysis. ImageJ software was used to quantify fluorescence intensity. Three independent experiments were performed per assay and reporter strain.

\subsection{Statistical Analysis}

The statistical analyses were performed using the PC software package SPSS (version 23.0; SPSS Inc., Chicago, IL, USA). Analysis of variance (ANOVA) was applied for multiple comparisons of values to determine possible significant differences between treated and control groups. To analyze survival to thermal stress, contingency tables were prepared, and statistical significance was calculated using the Chi Square Test.

\section{Results and Discussion}

\subsection{Assays in Wild Type and Mutant Worms}

An enhancement in the survival was observed in N2 wild-type worms treated with Q $200 \mu \mathrm{M}$ after being subjected to thermal stress compared with non-treated controls. Specifically, in the assays carried out on the second day of adulthood, the average proportion of living worms after stress was $64.78 \%$ in the control group and $81.11 \%$ in Q-treated worms $(p=0.000)$, while on the ninth day of adulthood, the survival rate was $35.1 \%$ in untreated worms and $47.2 \%$ in treated animals $(p=0.001)$ (Figure 2).

The molecular mechanisms involved in this enhancement of thermotolerance were explored, checking the ability of $Q$ to modulate the stress resistance in C. elegans mutant strains. Initially, the effect of $Q$ on thermal stress resistance was evaluated in worms carrying loss of function mutations in genes of the IIS pathway, namely age-1(hx546), akt-1(mg306), daf-2(e1370), and the double mutant akt-2(tm812); sgk-1(ft15), all of them long-lived and with greater resistance to stress than the wild-type strain. Similar to the wild-type, mutant worms were subjected to a thermal shock $\left(35^{\circ} \mathrm{C}, 6-8 \mathrm{~h}\right)$ on days 2 and 9 of adulthood. The obtained results showed that the stress resistance was not increased in any of the mutant worms treated with quercetin at either day 2 or 9 (Figure 3). These results suggested that age-1, akt-1,akt-2, sgk-1, and daf-2 were necessary to mediate stress resistance induced by Q in C. elegans. 
A) $2^{\text {nd }}$ of adulthood

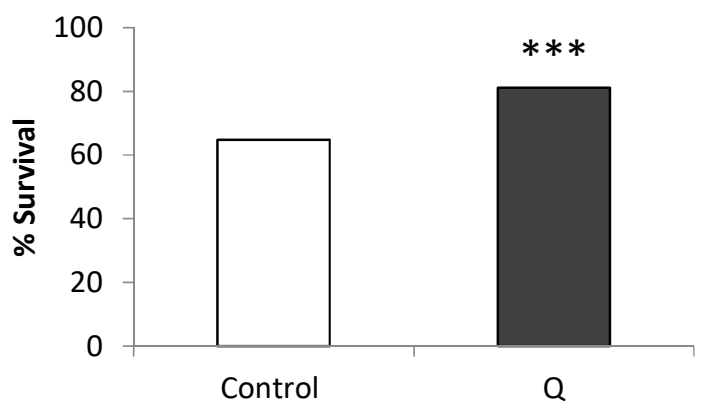

B) $9^{\text {th }}$ of adulthood

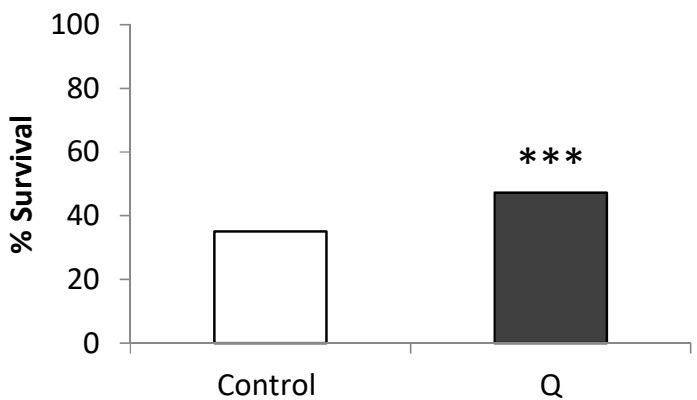

Figure 2. Percentages of survival following thermal stress $\left(35^{\circ} \mathrm{C}, 8 \mathrm{~h}\right)$ applied at days (A) 2 and (B) 9 of adulthood in N2 wild-type C. elegans strain not treated (controls) and treated with Q (200 $\mu \mathrm{M})$. Statistical significance was calculated using the Chi Square Test (200-300 individuals per assay in both controls and treated worms). The asterisks $\left(^{* * *}\right)$ indicate significant differences at $p<0.001$.

Pietsch et al. [11] also studied the effect of $Q$ in some of these mutants. As in our case, they did not find an improvement in the survival after thermal stress in daf-2 and age-1 mutants treated with $200 \mu \mathrm{M}$ quercetin, concluding that that those genes were required to mediate the stress-protective effects of the flavonol. However, they found that the treatment with $Q$ unexpectedly produced an improvement in the resistance to stress in the akt-2 mutant, a gene located downstream of DAF-2 and AGE-1 in the IIS pathway. They proposed that this could be explained because SGK-1 was more important for resistance to stress than the AKT kinases [11]. In the present study, no increase in the survival after thermal stress was observed in the double-mutant akt-2;sgk-1 treated with $\mathrm{Q}$ (Figure 3), suggesting that sgk-1 could actually be necessary to improve the resistance to stress by quercetin. Similarly, no changes in the survival after stress were produced in Q-treated akt-1 mutants, a gene that encodes an ortholog of serine/threonine kinase AKT/PKB and interacts with the IIS pathway. This indicates that the kinase akt-1 was also necessary for the improvement in the resistance to stress in C. elegans.

The resistance to thermal stress in response to $Q$ was also studied in daf-16, hsf-1, skn-1, daf-18, and $h s p-16.2$ mutant worms. The transcription factors DAF-16, HSF-1, and SKN-1 produce changes in the expression of several genes in response to a reduced IIS pathway. The genes regulated by these transcription factors are functionally relevant, including stress response genes, such as catalases, glutathione-S-transferases, metallothioneins, and genes that encode antimicrobial peptides, chaperones like hsp-16.2, apolipoproteins, and lipases [27]. As it can observed in Figure 4, the treatment with Q did not improve the survival in daf-18, skn-1, and $h s p-16.2$ mutants exposed to thermal stress, suggesting that these genes would be necessary to explain the effect of $Q$ in worm resistance against stress. However, the treatment with $Q$ continued to produce an improvement in the resistance to thermal stress in daf-16 and hsf-1 mutants, indicating that the effect of $Q$ in C. elegans was independent of these genes. Similar results on the influence of $Q$ were obtained in young and older adults in the studied mutants (Figure 4). 
$2^{\text {nd }}$ day of adulthood

A.1

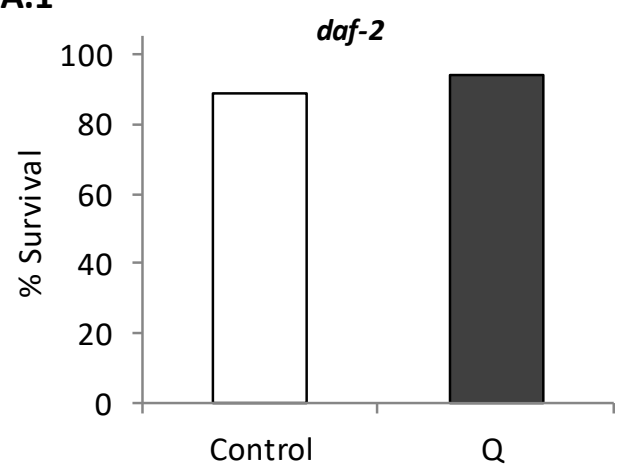

B.1

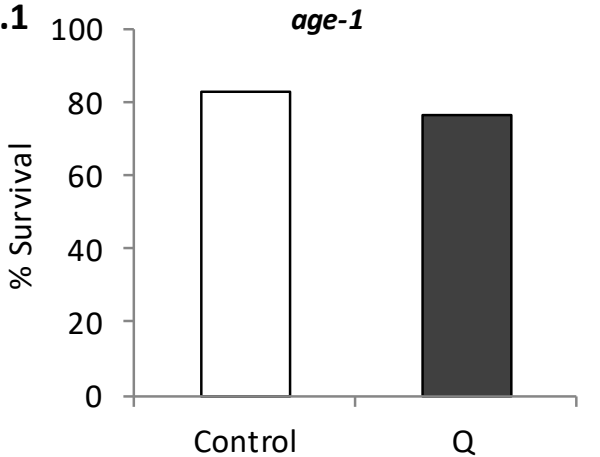

\section{C.1}
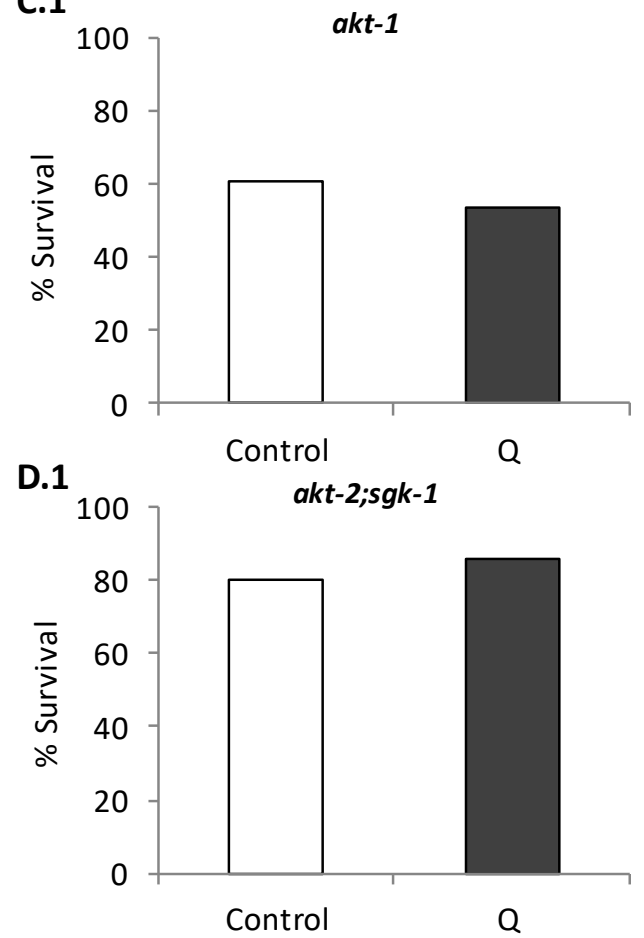

$9^{\text {th }}$ day of adulthood

A. 2
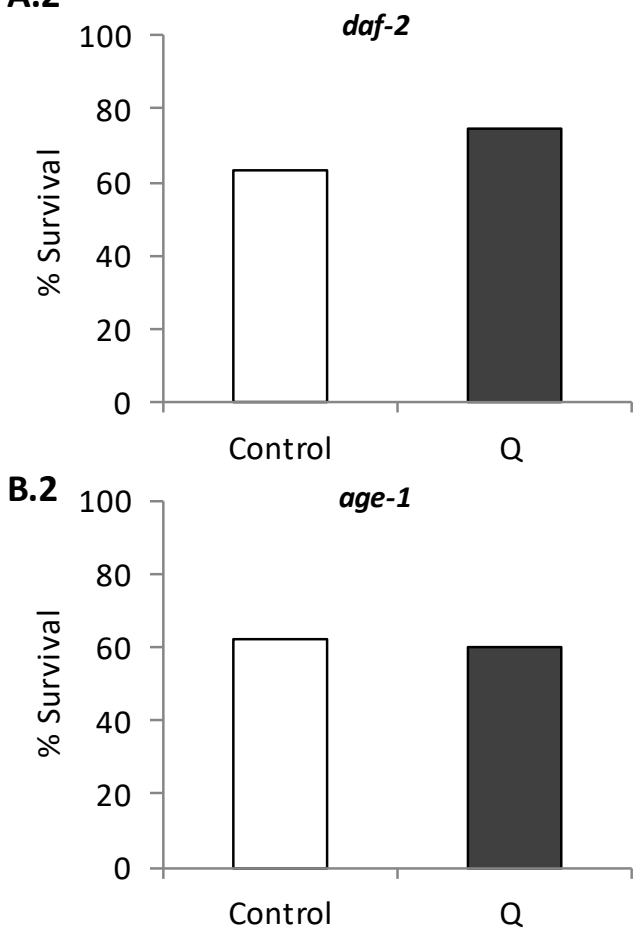

C.2
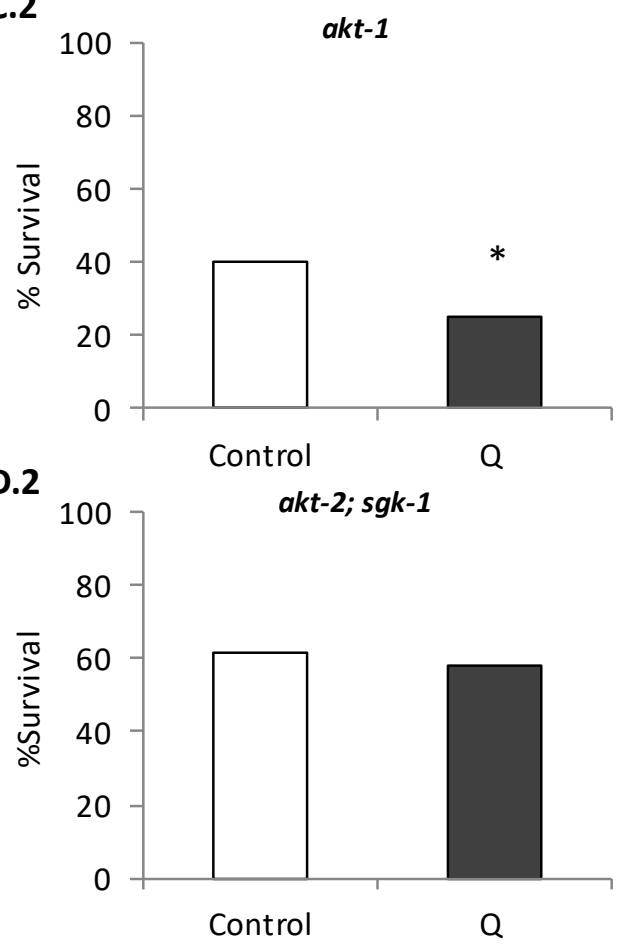

Figure 3. Percentages of survival following thermal stress $\left(35^{\circ} \mathrm{C}, 8 \mathrm{~h}\right)$ applied at days 2 (A-D.1) and 9 (A-D.2) of adulthood in different long-lived C. elegans mutants from the IIS pathway: daf-2(e1370) (A), age-1(hx546) (B), akt-1(mg306) and akt-2(tm812) (C); sgk-1(ft15) (D) cultivated in the absence (controls) and presence of $Q(200 \mu \mathrm{M})$. Statistical significance was calculated using the Chi Square Test. In both controls and treated worms, ten plates were used per assay containing 20 worms per plate (i.e., 200 worms in total). The asterisk (*) indicates significant differences at $p<0.05$. 
$2^{\text {nd }}$ day of adulthood

A.1
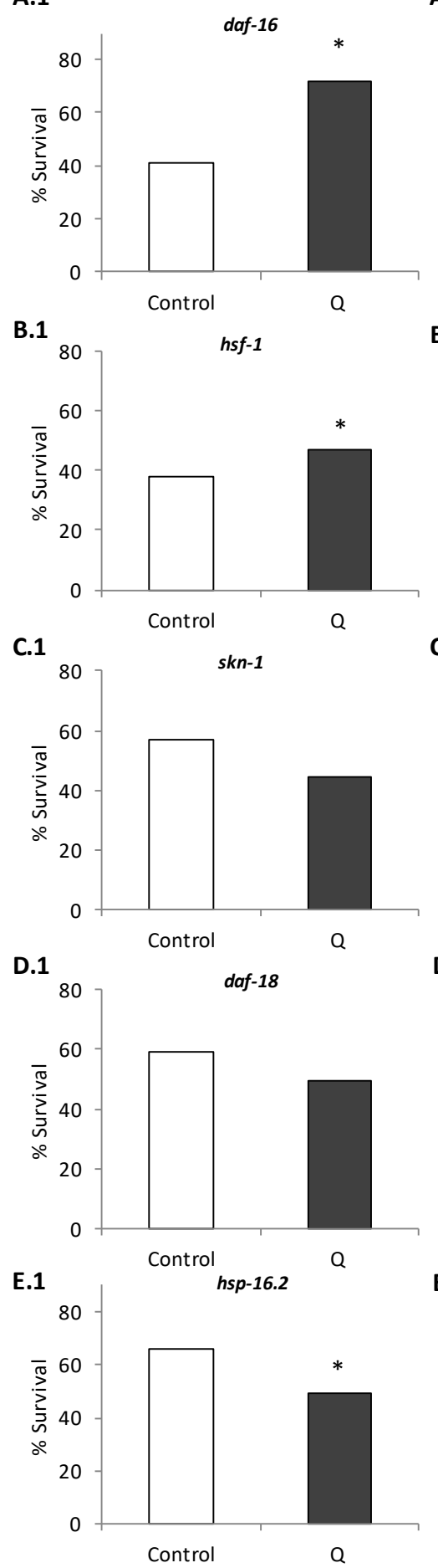

$9^{\text {th }}$ day of adulthood

A. 2

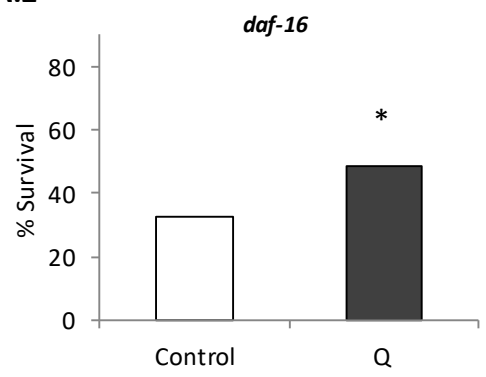

B.2 $80 \quad h s f-1$

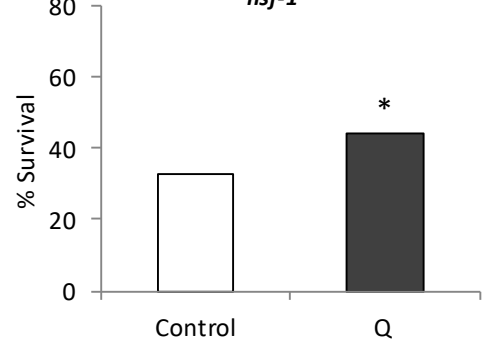

C.2 skn-1

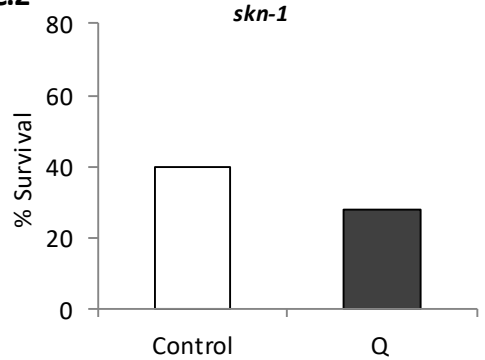

D.2 daf-18
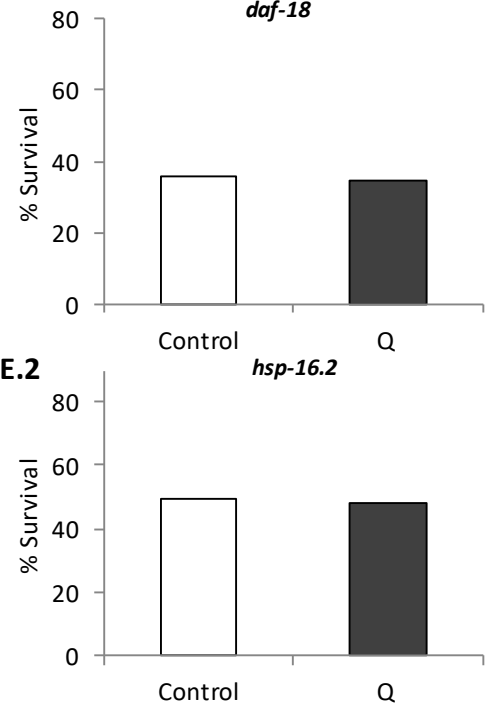

Figure 4. Percentages of survival following thermal stress $\left(35^{\circ} \mathrm{C}, 6 \mathrm{~h}\right.$; except for $\left.h s p-16.2\left(35^{\circ} \mathrm{C}, 4 \mathrm{~h}\right)\right)$ applied at days 2 (A-E.1) and 9 (A-E.2) of adulthood in daf-16 (mu86) (A), hsf-1(sy441) (B), skn-1(zu67) (C), daf-18(e1375) (D) and hsp-16.2(gk249) (E) mutants cultivated in the absence (controls) and presence of $Q(200 \mu \mathrm{M})$. Statistical significance was calculated using the Chi Square Test. In both controls and treated worms, ten plates were used per assay containing 20 worms per plate (i.e., 200 worms in total), but in the case of the $s k n-1$ mutant, 300 worms ( 20 worms per plate/15 plates) were used. The asterisk $\left(^{*}\right)$ indicates significant differences at $p<0.05$ on comparing with control. 


\section{2. q-RT-PCR Analyses}

The influence of quercetin on some transcription factors and target genes of the IIS pathway was also explored by quantification of the expression of daf-16, $h s f-1$, skn-1, daf-18, and $h s f-16.2$ by RT-qPCR in wild type worms, both submitted and not submitted to thermal stress $\left(5 \mathrm{~h}, 35^{\circ} \mathrm{C}\right)$ after growing 4 days in the presence of the flavonol. As it can be seen in Figure 5, the treatment with $Q$ did not modify the expression of daf-18 either after subjecting or not subjecting the worms to thermal stress. However, the results previously obtained with the mutants (Figure 4) indicated that daf-18 could be involved in the protective effects of quercetin against stress. A possible explanation to this apparent contradiction could be that the result obtained in the daf-18 mutant is rather reflecting the involvement of the protein kinase AGE-1, as the DAF-18/phosphatase and tensin homolog (PTEN)protein is responsible for dephosphorylating and inhibiting AGE-1/PI3K, counteracting its activity [21]. Another possibility is that DAF-18 was regulated by quercetin at the post-transcriptional or activity level.

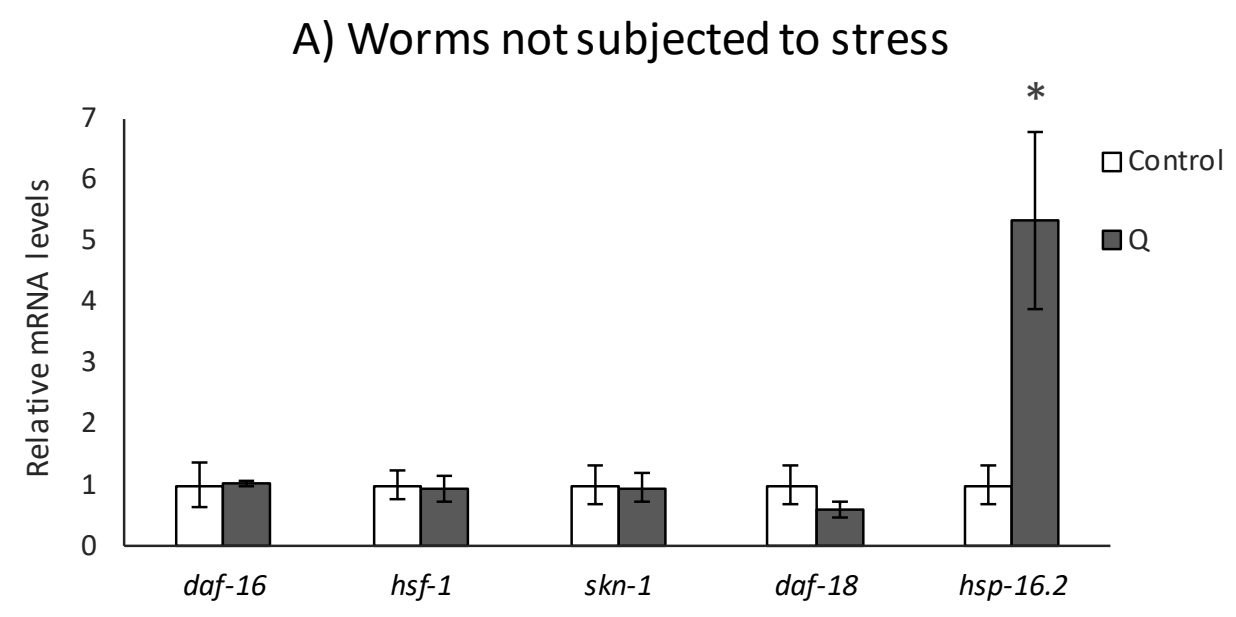

\section{B) Worms subjected to stress}

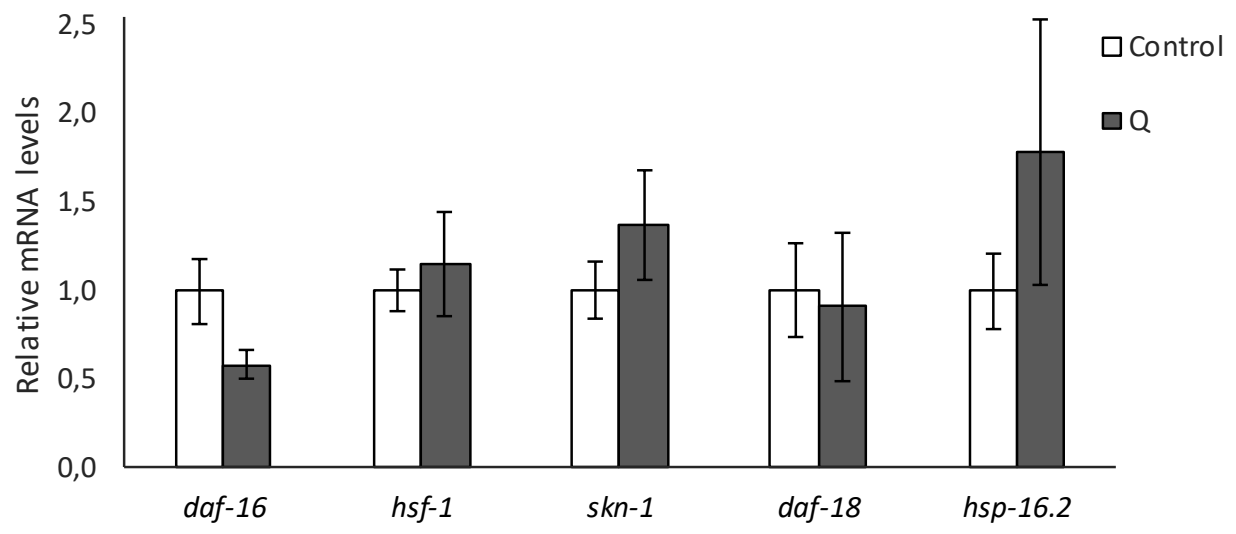

Figure 5. Effect of $\mathrm{Q}$ on the expression of daf-16, hsf-1, skn-1, daf-18, and $h s p-16.2$ genes in N2 C. elegans cultivated in the absence (controls) and presence of $Q(200 \mu \mathrm{M})(\mathbf{A})$ under non-stressed conditions or (B) after subjecting them to thermal stress. The expression level was determined by RT-qPCR. act-1 was used as housekeeping control. Nine independent experiments were performed. The results are presented as the mean values \pm Standard Error of the Mean (SEM). Statistical significance was calculated using by one-way analysis of variance (ANOVA). The asterisk $\left(^{*}\right)$ indicates significant differences at $p<0.05$. 
Similarly, the expression of $h s f-1$ was not modified by the treatment with Q, neither in normal growing conditions nor after application of thermal stress $\left(35^{\circ} \mathrm{C}, 5 \mathrm{~h}\right)$ (Figure 5). This result would confirm that the heat transcription factor $h s f-1$ is not involved in the effects of $Q$ on stress resistance, supporting the above-described observations on $h s f-1$ mutants (Figure 4). In a previous study on $h s f-1$ loss of function mutants, Fitzenberger et al. [28] also found that this gene was not required to explain the ability of $Q$ to prevent the glucose-induced reduction of survival in C. elegans.

The treatment with $Q$ did not produce changes in the expression of daf-16 (Figure 5). Together with the findings obtained in the assays with mutants, these results seem to confirm that the effect of $\mathrm{Q}$ on worm stress resistance is independent of daf-16. Other authors had already studied the involvement of daf-16 in the effects of $Q$ using knockout worms [10,11,13], finding that $Q$ continued improving longevity and resistance to thermal and hydrogen peroxide-induced oxidative stress in daf-16 mutants, which suggest that this gene was not essential for the effects of quercetin, observations that are consistent with the results obtained herein, either in worms subjected or not subjected to stress.

SKN-1 is the homologue of Nrf-2 transcription factor, which regulates oxidative stress response and lifespan, mobilizing the conserved phase 2 detoxification response [29]. No differences were found in the expression of $s k n-1$ between worms treated or not treated with $\mathrm{Q}$ and not subjected to stress (Figure 5A), which seems in agreement with the observations of Pietsch et al. [11], who reported that quercetin induced an increase in the lifespan of $s k n-1$ mutants under normal growth conditions, indicating that the effects of this flavonoid in the absence of stress are independent of that gene. However, the results obtained with the $s k n-1$ mutants (Figure 4 ) indicated that this gene is a mediator in the protective effects of $Q$ against stress. Tullet et al. [29,30] suggested that $S K N-1$ is a transcriptional co-regulator of DAF-16 regarding resistance to oxidative stress and the expression of detoxification genes in response to a reduced IIS signal, but it extends worm half-life independently of DAF-16. This dual function of $s k n-1$ might be coherent with the results observed herein, where $\mathrm{Q}$ did not change the skn-1 expression in absence of stress, although this gene seems to be necessary in the improvement of resistance to thermal stress mediated by $\mathrm{Q}$.

The influence of $Q$ on thermal shock proteins HSP-16.2, whose expression is influenced by the IIS, was also studied. As shown in Figure 5, the treatment with $Q$ induced an increase in the expression of $h s p-16.2$, either without or with stress. However, the differences were more noticeable in the absence of stress, which could possibly be explained by the already strong induction of HSP-16.2 caused by the thermal stress, which would make the effect induced by $Q$ treatment less relevant. Together with the results in the $h s p-16.2$ mutants, where a decrease in the resistance to thermal stress was observed in quercetin-treated worms (Figure 4), it appears that thermal shock proteins can be involved in the protective effects of the flavonol against stress.

All in all, the obtained results showed that, at least in part, the IIS pathway would be involved in the improvement to thermotolerance induced by Q, entailing the genes age-1, akt-1, akt-2, sgk-1, daf-2, daf-18, skn-1, and $h s p-16.2$, but independent of daf-16 and $h s f-1$. In addition, the involvement of these genes was not modified by the age of the worm. Previous studies by our group with epicatechin also showed that the enhanced stress resistance induced by this flavan-3-ol in C. elegans was also mediated by the IIS pathway, although it did not necessarily involve the same genes, as in that case the expression levels of the main transcription factors of the pathway (daf-16, skn-1, and $h s f-1$ ) were modified by the compound [31]. Actually, even compounds belonging to the same flavonoid class seem to act through different mechanisms. Thus, the lifespan extension produced by quercetin-3-O-diglucoside in C. elegans was explained by upregulation of the genes daf-2, old-1, osr-1, and sek-1, whereas no modification was produced in the expression of daf-16, age-1, and sir-2.1 [12]. However, assays with a flavonol-rich extract obtained from Baccharis trimera concluded that the improvement in the stress resistance was independent of several stress-related signaling pathways (p38, JNK, and ERK) and transcription factors SKN-1 and DAF-16 [32]. 


\subsection{Assays with Fluorescent Reporters}

The insulin signaling pathway transmits signals in response to the environmental conditions that could change the expression of different genes related to stress and longevity, thus regulating important processes such as aging, metabolism, or dauer formation. The expression of some such genes, namely those encoding heat shock proteins ( $h s p-16.2$ and $h s p-70)$ and antioxidant enzymes (sod-3 and gst-4), was assessed in order to gain further insight into the mechanisms of action underlying the effects of $Q$ on the modulation of lifespan and stress in C. elegans. With this aim, transgenic strains that express GFP under the control of $g s t-4, s o d-3, h s p-16.2$, and $h s p-70$ promoters were employed. GFP expression levels were analyzed in animals grown in the presence or absence of quercetin under non-stress conditions for Pgst-4::gfp and Psod-3::gfp reporters, whereas for Phsp-70::gfp and Phsp-16.2::gfp reporters, worms were previously submitted to a heat shock $\left(35^{\circ} \mathrm{C}, 1 \mathrm{~h}\right)$ and further allowed to recover for $3 \mathrm{~h}(\mathrm{hsp}-70)$ or $2 \mathrm{~h}(\mathrm{hsp}-16.2)$ at $20^{\circ} \mathrm{C}$.

As it can be seen in Figure 6, the treatment with $Q$ did not produce an increase in the expression of any of the studied genes ( $g s t-4$, sod-3, $h s p-16.2$, and $h s p-70$ ) in young worms of reproductive age. Indeed, there was even a decrease in the expression of $h s p-70$ in the worms treated with $\mathrm{Q}(p=0.018)$. The expression of $h s p-16.2$ and sod-3 was also studied using reporter strains in older worms (day 9), in order to establish if the mechanism of action underlying the effects of $Q$ was dependent on the age of the worm. Similar results were obtained regarding the expression of sod-3 (Figure 7) as compared to younger worms (Figure 6), finding no differences in the expression by the treatment with Q. However, the expression of $h s p-16.2$ was increased by the treatment with $Q$ at day $9(p=0.008)$ (Figure 7), which was not observed at day 2 (Figure 6).

Some of these genes have already been studied by other authors using fluorescent reporters to explore worm response to $\mathrm{Q}$, specifically gst-4 and sod-3. Opposed results were reported regarding the effects of Q on sod-3. Whereas, Kampkötter et al. [9] observed a decrease in the expression of sod-3 in worms exposed to $100 \mu \mathrm{M} Q$, Grünz et al. [13] found that growing the worms in the presence of $100 \mu \mathrm{M}$ of $\mathrm{Q}$ produced a significant increase in sod-3 expression. As for the present study, no significant changes were detected in the expression of sod-3 after treatment with $200 \mu \mathrm{M}$ of $\mathrm{Q}$ in any of the two days studied. On the other hand, Kampkötter et al. [14] observed that the expression of gst-4 was not modified by Q $100 \mu \mathrm{M}$ under normal growth conditions, although it decreased the expression of $g s t-4$ when worms were subjected to oxidative stress with juglone $20 \mu \mathrm{M}$ [14]. Those results would be in agreement with the observations made herein, where no increase in the expression of $g s t-4$ was found under normal growth conditions $(200 \mu \mathrm{M} \mathrm{Q})$.

The results for Phsp-16::gfp obtained at different ages of the worms could help to understand the effects of increased lifespan and improvement of resistance to stress induced by Q in C. elegans, since many heat shock proteins are regulated positively at the beginning of adult life to further decrease throughout life [33]. The obtained result might indicate that this decrease could be reversed by the treatment with Q. It is pertinent to indicate that in previous studies on longevity, greater survival started to be observed from approximately day 8 onwards in worms treated with quercetin in relation to non-treated worms [8], suggesting changes in C. elegans metabolism favored by prolonged exposure to the flavonol, among which, the upregulation of some heat shock proteins could be involved. Actually, the increased lifespan and thermotolerance observed in certain mutants, such as the long-lived age-1, have been explained by an increase in the regulation and accumulation of HSP-16 [34]. The involvement of $h s p-16.2$ was also supported by the increase in the expression of $h s p-16.2$ found in the RT-qPCR studies (Figure 5) and the loss of the improvement in resistance to thermal stress in the hsp-16.2 mutant (Figure 4). On the other hand, the results showed a decrease in the reporter of $h s p-70$ in worms treated with Q (Figure 6). Differences in the expression of genes encoding distinct heat shock proteins, were also found by Pietsch et al. [15], observing that Q produced an increase in the expression of $h s p-3$, $h s p-12.6, h s p-16.1$, and $h s p-16.41$, but a decrease of $h s p-70$ and $h s p-17$. 
Pgst-4::gfp

A)
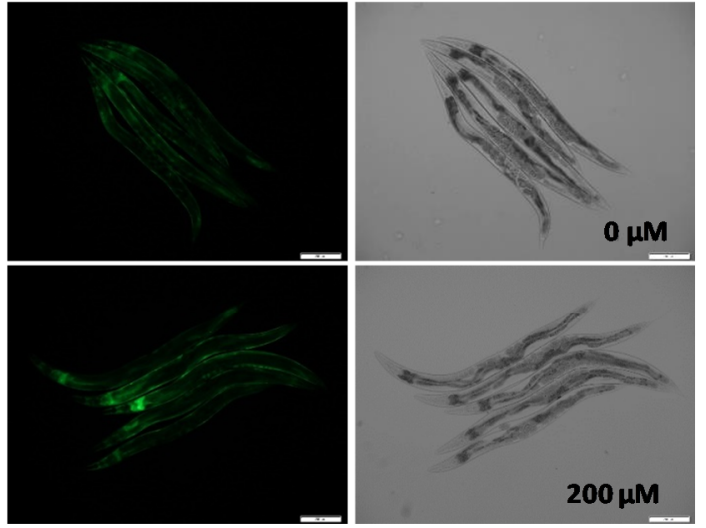

Phsp-70::gfp
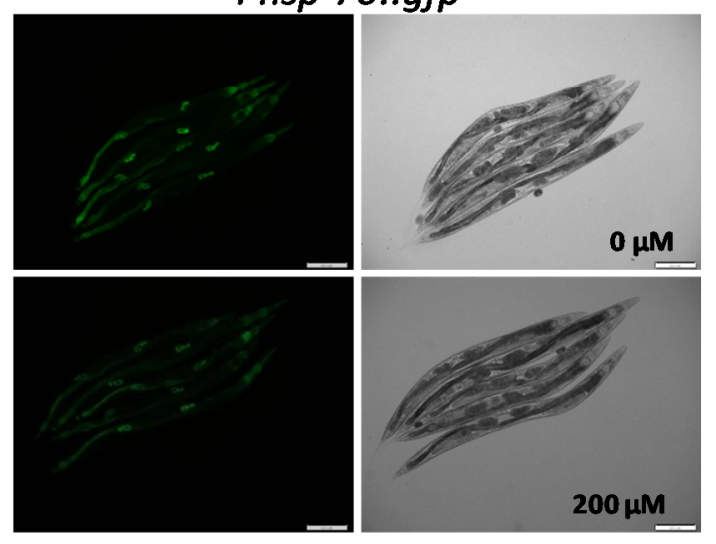

B)

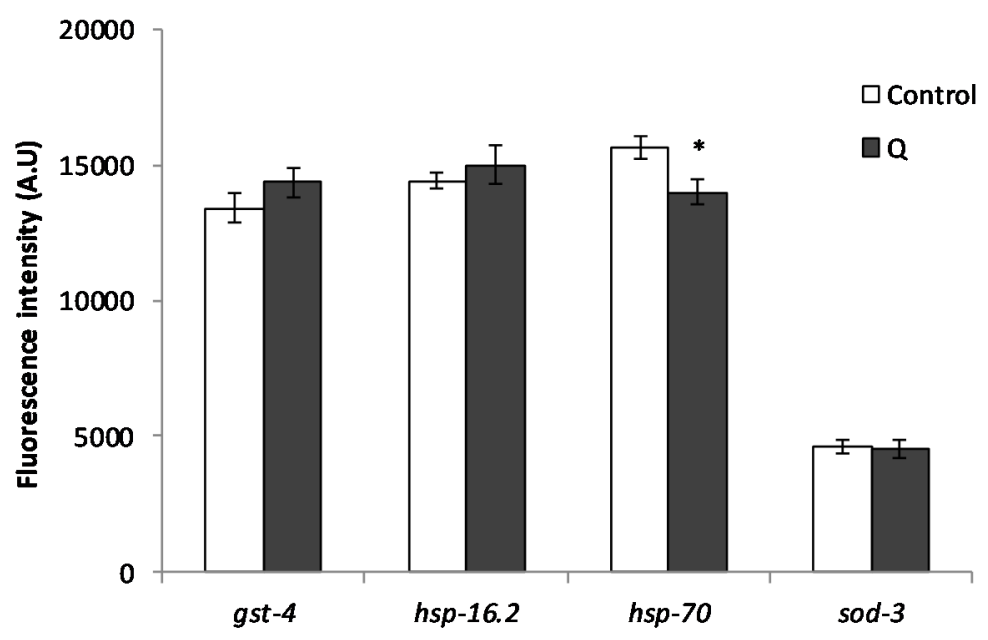

Figure 6. Effect of $\mathrm{Q}$ on the expression of $g s t-4, h s p-16.2, h s p-70$, and sod-3 after cultivation of $C$. elegans in the absence and presence of $\mathrm{Q}(200 \mu \mathrm{M})$. (A) Representative fluorescence images of control and Q-treated worm strains. (B) Quantification of the relative fluorescence intensities of transgenic worms. Total green fluorescent protein (GFP) fluorescence of each whole worm was quantified using Image J software. Three independent experiments were performed. The results are presented as the mean values \pm SEM. Approximately 35 randomly selected worms from each set of experiments were examined. Differences compared with the control ( $0 \mu \mathrm{M}$ Q, $0.1 \%$ dimethyl sulfoxide (DMSO)) were considered statistically significant at ${ }^{*}(p<0.05)$ by one-way ANOVA. 


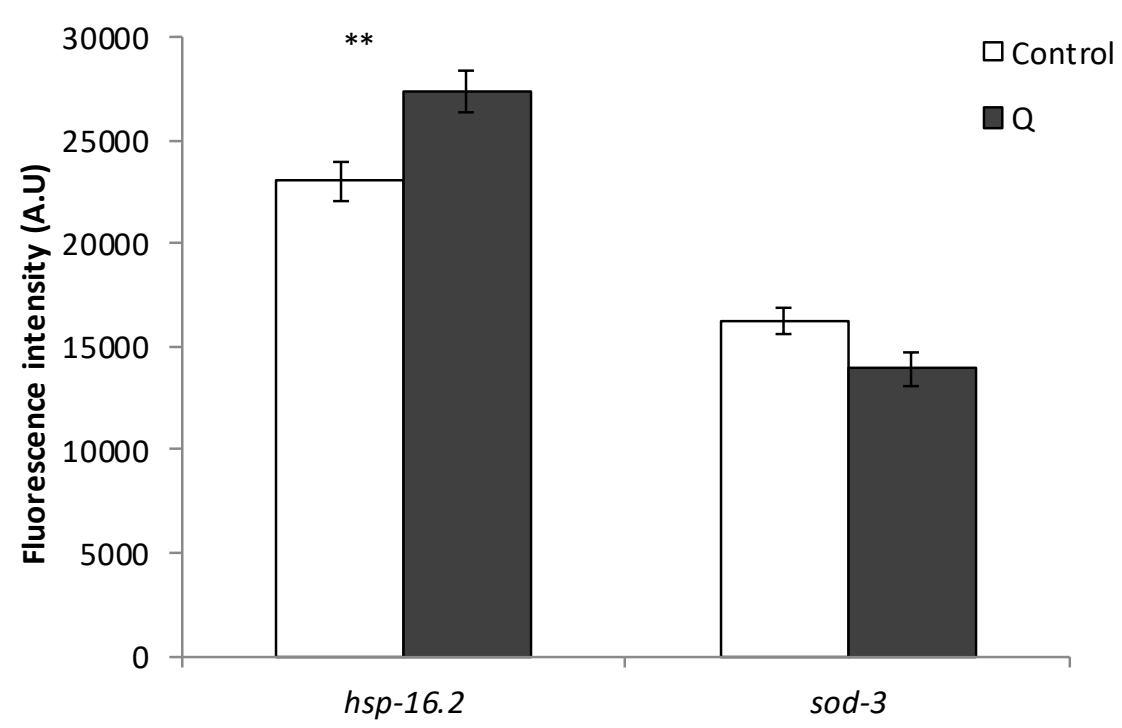

Figure 7. Effect of $Q$ on the expression of $h s p-16.2$ and sod-3 in old worms (day 9 of adulthood) after cultivation of $C$. elegans in the absence and presence of Q $(200 \mu \mathrm{M})$. Total GFP fluorescence of each whole worm was quantified using Image J software. Three independent experiments were performed. The results are presented as the mean values \pm SEM. Approximately 35 randomly selected worms from each set of experiments were examined. Differences compared with the control ( $0 \mu \mathrm{M} \mathrm{Q}, 0.1 \% \mathrm{DMSO})$ were considered statistically significant at ${ }^{* *}(p<0.01)$.

The modulation of the subcellular localization of the DAF-16 forkhead transcription factor was examined using a transgenic strain expressing a fusion protein DAF-16::GFP. The treatment with Q did not affect the translocation of DAF-16 to the nucleus with respect to the control worms, neither under normal growth conditions nor after thermal stress (Figure 8). The localization of DAF-16 was also studied in older worms (day 9), obtaining similar results that at day 2 regarding its subcellular localization.

As discussed above, the treatment with $Q$ did not produce an increase in the expression of daf-16 in any of the assayed conditions, while it led to an increase in the resistance to thermal stress on daf-16 mutant strains. All these results indicate that the effect of this flavonol in the improvement of worm resistance to stress is independent of daf-16. A similar conclusion has been obtained by some authors $[10,11]$, although others observed greater translocation of DAF-16 from the cytosol to the nucleus following $Q$ treatment $[9,13,14]$. In this respect, Saul et al. [10] suggested that the translocation of DAF-16 to the nucleus in response to quercetin could be more of a circumstantial effect than proof of an underlying longevity mechanism. In fact, although DAF-16 is a key factor in the control of stress response and longevity $[17,35,36]$, it has also been pointed out that its translocation to the nucleus does not guarantee a longer lifespan, suggesting that DAF-16 would not necessarily act only in the regulation of longevity [37,38].

The finding that the effects of $Q$ can be independent of daf- 16 but dependent on daf-2 and other components of the IIS, such as akt-1, age-1, and akt-2/sgk-1, could appear surprising. Nevertheless, Hekimi et al. [37] and Lin et al. [39] pointed out that when the IIS pathway is altered in response to different environmental signals, besides the stress resistance genes, other unidentified signals are regulated by daf-2, which are not dependent on daf-16, but that are also essential for the extended longevity in daf-2 mutants.

In the end, the obtained results indicated that two key transcription factors that could be involved in the expression of heat shock proteins, DAF-16 and HSF-1 [40], were not related with the effects exerted by Q on C. elegans (Figures 4 and 5). Actually, it is described that HSF-1 is not a key factor for all HSPs [41]. Mertenskötter et al. [42] showed that in the expression of chaperone genes, protein biosynthesis and protein degradation was positively influenced by the MAPK pathway and established 
the importance of this pathway in heat stress responses, possibly by a PMK-1-mediated activation of the transcription factor SKN-1 in C. elegans. Other authors have also found that components of related pathways, such as UNC-43, SEK-1, and OSR-1 are involved in the molecular mechanisms of the response to quercetin and other polyphenols $[11,43,44]$. Thus, the MAPK pathways could also be implicated in the effects of quercetin, which might contribute to explain the role of SKN-1 and the activation of certain HSPs observed in the present study.

A)

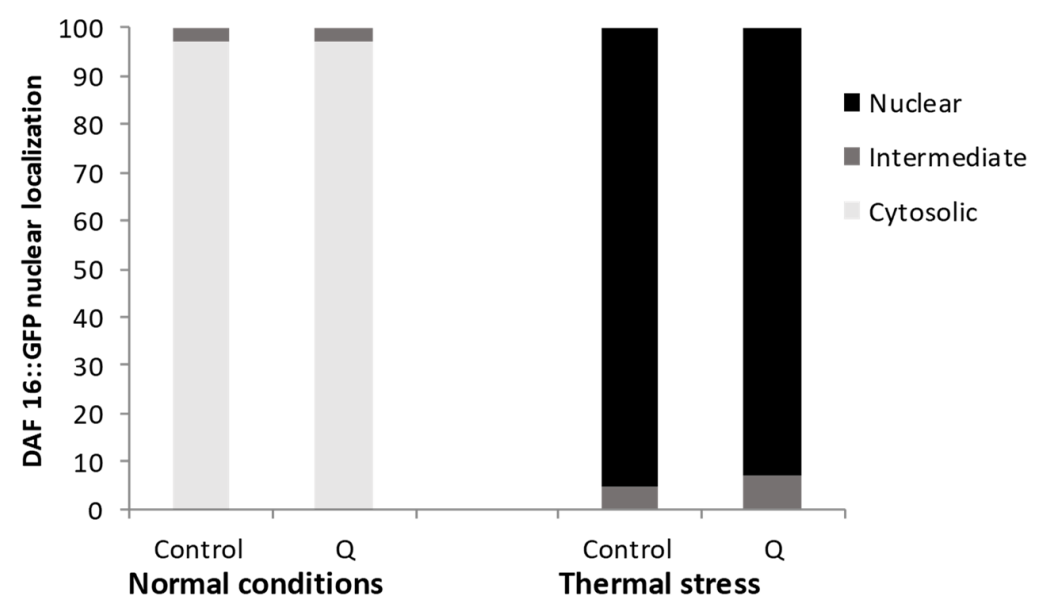

B)

Cytosolic
Intermediate
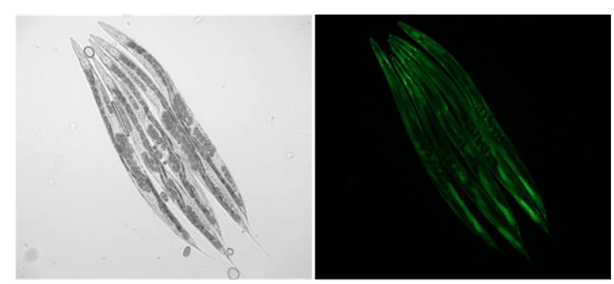

Intermediate
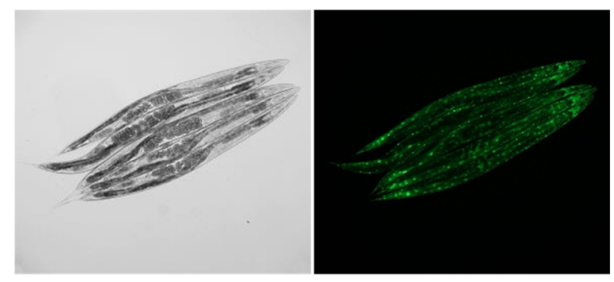

Nuclear

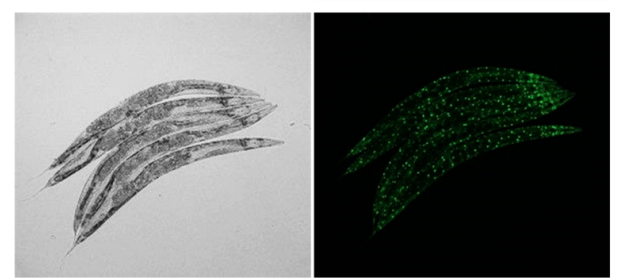

Figure 8. (A) Effect of Q on DAF-16::GFP subcellular distribution and (B) representative pictures of the subcellular location of DAF-16::GFP, i.e., cytosolic, intermediate and nuclear. Transgenic worms expressing the fusion protein DAF-16::GFP were cultivated in the absence (controls) and presence of $Q(200 \mu \mathrm{M})$ after subjecting or not subjecting the worms to thermal stress and evaluated at day 2 of adulthood.

\section{Conclusions}

The enhancement of the oxidative stress resistance of C. elegans induced by $Q$ could be explained, at least in part, by the modulation of the insulin signaling pathway, namely the genes age-1, akt-1, akt-2, 
daf-18, sgk-1, daf-2, skn-1, and hsp-16.2. However, this effect would be independent of daf-16 and $h s f-1$. The implication of $d a f-2$ and not of $d a f-16$ in the observed effects seems to reinforce the idea that there are signals regulated by $d a f-2$ independent of $d a f-16$ that are also essential for the extension of longevity and resistance to stress.

The expression of $s k n-1$ was not changed by the treatment with $Q$ when worms were submitted to stress, but the results obtained in the $s k n-1$ mutants pointed out that it was necessary to mediate the resistance to thermal stress. It has been reported that SKN-1 promotes longevity by a different mechanism to the protection against oxidative damage [29,30], and also that the increase of lifespan by $Q$ was maintained in $s k n-1$ mutants [11]. This could explain why quercetin does not alter $s k n-1$ expression under normal conditions, while this gene seems involved in the increased resistance to stress induced by $Q$.

The studies with transgenic strains showed that $Q$ did not produce an increase in the expression of the antioxidant enzymes GST-4 and SOD-3, nor of the heat shock proteins HSP-16.2 and HSP-70 in young worms, whereas an increase was produced in the expression of HSP-16.2 in aged worms. This observation could be important to explain, at least in part, the effects of enhanced lifespan and greater resistance to stress produced by $\mathrm{Q}$ in C. elegans, since the expression of many heat shock proteins diminishes throughout worm life, a process that might be counteracted by this flavonol.

In summary, the network of signaling pathways that could be modulated by quercetin and other flavonoids is diverse and complex, and the molecular mechanisms of action can vary depending on the compound. For instance, while DAF-16 and HSF-1 transcription factors were previously demonstrated to be involved in the effects of epicatechin [31], they do not seem to be required in the stress resistance effects of $Q$. In this work, just the insulin signaling pathway has been explored, but other routes are surely involved, which should be considered in future studies.

Supplementary Materials: The following are available online at http://www.mdpi.com/2076-3921/8/12/585/s1, Table S1: Oligonucleotide sequence of primers used to determine the expression levels of C. elegans genes by RT-QPCR.

Author Contributions: Conceptualization, C.S.-B. and A.M.G.-P.; Methodology B.A.-D., S.G.-M. and M.R.R.; Formal Analysis, B.A.-D., E.S.-H., M.D. and S.G.-M.; Resources, C.S.-B., A.M.-V, M.R.R. and A.M.G.-P.; Writing-Original Draft Preparation, B.A.-D. and C.S.-B.; Writing-Review and Editing, B.A.-D., C.S.-B., A.M.G.-P. and A.M.-V.; Supervision, C.S.-B., A.M.G.-P. and A.M.-V.; Project Administration, C.S.-B., A.M.G.-P. and A.M.-V.; Funding Acquisition, C.S.-B., A.M.G.-P. and A.M.-V.

Funding: This research was funded by the Spanish Ministerio de Economía y Competitividad (MINECO Projects AGL2015-64522-C2 and BFU2015-64408-P) and Fondo Europeo de Desarrollo Regional (FEDER)-Interreg España-Portugal Programme (Project ref. 0377_IBERPHENOL_6_E).

Acknowledgments: The authors are thankful to Francisco J. Martín-Vallejo for statistical advice.

Conflicts of Interest: The authors declare no conflict of interest.

\section{References}

1. Kaliora, A.C.; Dedoussis, G.V. Natural antioxidant compounds in risk factors for CVD. Pharm. Res. 2007, 56, 99-109. [CrossRef] [PubMed]

2. Boots, A.W.; Haenen, G.R.; Bast, A. Health effects of quercetin: From antioxidant to nutraceutical. Eur. J. Pharm. 2008, 585, 325-337. [CrossRef] [PubMed]

3. Darband, S.G.; Kaviani, M.; Yousefi, B.; Sadighparvar, S.; Pakdel, F.G.; Attari, J.A.; Mohebbi, I.; Naderi, S.; Majidinia, M. Quercetin: A functional dietary flavonoid with potential chemo-preventive properties in colorectal cancer. J. Cell. Physiol. 2018, 233, 6544-6560. [CrossRef] [PubMed]

4. Cos, P.; Ying, L.; Calomme, M.; Hu, J.P.; Cimanga, K.; Van Poel, B.; Pieters, L.; Vlietinck, A.J.; Vanden Berghe, D. Structure-activity relationship and classification of flavonoids as inhibitors of xanthine oxidase and superoxide scavengers. J. Nat. Prod. 1998, 61, 71-76. [CrossRef] [PubMed]

5. Middleton, E.; Kandaswami, C.; Theoharides, T.C. The effects of plant flavonoids on mammalian cells: Implications for inflammation, heart disease, and cancer. Pharm. Rev. 2000, 52, 673-751. [PubMed] 
6. González-Paramás, A.M.; Ayuda-Durán, B.; Martínez, S.; González-Manzano, S.; Santos-Buelga, D. The Mechanisms Behind the Biological Activity of Flavonoids. Curr. Med. Chem. 2018, 26, 1-14. [CrossRef]

7. Kyriakakis, E.; Markaki, M.; Tavernarakis, N. Caenorhabditis elegans as a model for cancer research. Mol. Cell. Oncol. 2015, 2, e975027. [CrossRef]

8. Surco-Laos, F.; Cabello, J.; Gómez-Orte, E.; González-Manzano, S.; González-Paramás, A.M.; Santos-Buelga, C.; Dueñas, M. Effects of O-methylated metabolites of quercetin on oxidative stress, thermotolerance, lifespan and bioavailability on Caenorhabditis elegans. Food Funct. 2011, 2, 445-456. [CrossRef]

9. Kampkötter, A.; Timpel, C.; Zurawski, R.F.; Ruhl, S.; Chovolou, Y.; Proksch, P.; Wätjen, W. Increase of stress resistance and lifespan of Caenorhabditis elegans by quercetin. Comparative Biochemistry and Physiology. Comp. Biochem. Part B 2008, 149, 314-323. [CrossRef]

10. Saul, N.; Pietsch, K.; Menzel, R.; Steinberg, C.E. Quercetin-mediated longevity in C. elegans: Is DAF-16 involved? Mech. Ageing Dev. 2008, 129, 611-613. [CrossRef]

11. Pietsch, K.; Saul, N.; Menzel, R.; Stürzenbaum, S.R.; Steinberg, C.E. Quercetin mediated lifespan extension in Caenorhabditis elegans is modulated by age-1, daf-2, sek-1 and unc-43. Biogerontology 2009, 10, 565-578. [CrossRef] [PubMed]

12. Xue, Y.L.; Ahiko, T.; Miyakawa, T.; Amino, H.; Hu, F.; Furihata, K.; Kita, K.; Shirasawa, T.; Sawano, Y.; Tanokura, M. Isolation and Caenorhabditis elegans lifespan assay of flavonoids from onion. J. Agric. Food Chem. 2011, 59, 5927-5934. [CrossRef]

13. Grünz, G.; Haas, K.; Soukup, S.; Klingenspor, M.; Kulling, S.E.; Daniel, H.; Spanier, B. Structural features and bioavailability of four flavonoids and their implications for lifespan-extending and antioxidant actions in C. elegans. Mech. Ageing Dev. 2012, 133, 1-10. [CrossRef] [PubMed]

14. Kampkötter, A.; Nkwonkam, C.G.; Zurawski, R.F.; Timpel, C.; Chovolou, Y.; Wätjen, W.; Kahl, R. Investigations of protective effects of the flavonoids quercetin and rutin on stress resistance in the model organism Caenorhabditis elegans. Toxicology 2007, 234, 113-123. [CrossRef] [PubMed]

15. Pietsch, K.; Saul, N.; Chakrabarti, S.; Stürzenbaum, S.R.; Menzel, R.; Steinberg, C.E. Hormetins, antioxidants and prooxidants: Defining quercetin-, caffeic acid- and rosmarinic acid-mediated life extension in C. elegans. Biogerontology 2011, 12, 329-347. [CrossRef]

16. Dueñas, M.; Surco-Laos, F.; González-Manzano, S.; González-Paramás, A.M.; Gómez-Orte, E.; Cabello, J.; Santos-Buelga, C. Deglycosylation is a key step in biotransformation and lifespan effects of quercetin-3-O-glucoside in Caenorhabditis elegans. Pharmacol. Res. 2013, 76, 41-48. [CrossRef]

17. Oh, S.W.; Mukhopadhyay, A.; Svrzikapa, N.; Jiang, F.; Davis, R.J.; Tissenbaum, H.A. JNK regulates lifespan in Caenorhabditis elegans by modulating nuclear translocation of forkhead transcription factor/DAF-16. Proc. Natl. Acad. Sci. USA 2005, 102, 4494-4499. [CrossRef]

18. Troemel, E.R.; Chu, S.W.; Reinke, V.; Lee, S.S.; Ausubel, F.M.; Kim, D.H. p38 MAPK regulates expression of immune response genes and contributes to longevity in C. elegans. PLoS Genet. 2006, 2, e183. [CrossRef]

19. Altintas, O.; Park, S.; Lee, S.J.V. The role of insulin/IGF-1 signaling in the longevity of model in vertebrates, $C$. Elegans D. Melanogaster. BMB Rep. 2016, 49, 81-92. [CrossRef]

20. Lapierre, L.R.; Hansen, M. Lessons from C. elegans: Signaling pathways for longevity. Trends Endocrin. Met. 2012, 23, 637-644. [CrossRef]

21. Kimura, K.D.; Tissenbaum, H.A.; Liu, Y.; Ruvkun, G. Daf-2, an insulin receptor-like gene that regulates longevity and diapause in Caenorhabditis elegans. Science 1997, 277, 942-946. [CrossRef] [PubMed]

22. Ogg, S.; Paradis, S.; Gottlieb, S.; Patterson, G.I.; Lee, L.; Tissenbaum, H.A.; Ruvkun, G. The fork head transcription factor DAF-16 transduces insulin-like metabolic and longevity signals in C. elegans. Nature 1997, 389, 994-999. [CrossRef] [PubMed]

23. Mohri-Shiomi, A.; Garsin, D.A. Insulin signaling and the heat shock response modulate protein homeostasis in the Caenorhabditis elegans intestine during infection. J. Biol. Chem. 2008, 283, 194-201. [CrossRef] [PubMed]

24. Mansuri, M.L.; Parihar, P.; Solanki, I.; Parihar, M.S. Flavonoids in modulation of cell survival signaling pathways. Genes Nutr. 2014, 9, 400. [CrossRef]

25. Zevian, S.C.; Yanowitz, J.L. Methodological considerations for heat shock of the nematode Caenorhabditis elegans. Methods 2014, 68, 450-457. [CrossRef]

26. Livak, K.J.; Schmittgen, T.D. Analysis of relative gene expression data using real-time quantitative PCR and the $2^{-\Delta \Delta C T}$ method. Methods 2001, 25, 402-408. [CrossRef] 
27. Kenyon, C.J. The genetics of ageing. Nature 2010, 464, 504-512. [CrossRef]

28. Fitzenberger, E.; Deusing, D.J.; Marx, C.; Boll, M.; Lüersen, K.; Wenzel, U. The polyphenol quercetin protects the mev-1 mutant of Caenorhabditis elegans from glucose-induced reduction of survival under heat-stress depending on SIR-2.1, DAF-12, and proteasomal activity. Mol. Nutr. Food Res. 2014, 58, 984-994. [CrossRef]

29. Tullet, J.M.; Hertweck, M.; An, J.H.; Baker, J.; Hwang, J.Y.; Liu, S.; Oliveira, R.P.; Baumeister, R.; Blackwell, T.K. Direct inhibition of the longevity-promoting factor SKN-1 by insulin-like signaling in C. elegans. Cell 2008, 132, 1025-1038. [CrossRef]

30. Tullet, J.M.A.; Green, J.W.; Au, C.; Benedetto, A.; Thompson, M.A.; Clark, E.; Gilliat, A.F.; Young, A.; Schmeisser, K.; Gems, D. The SKN-1/Nrf2 transcription factor can protect against oxidative stress and increase lifespan in C. elegans by distinct mechanisms. Aging Cell 2017, 16, 1191-1194. [CrossRef]

31. Ayuda-Durán, B.; González-Manzano, S.; Miranda-Vizuete, A.; Dueñas, M.; Santos-Buelga, C.; González-Paramás, A.M. Epicatechin modulates stress-resistance in C. elegans via insulin/IGF-1 signaling pathway. PLoS ONE 2019, 14, e0199483. [CrossRef] [PubMed]

32. Paiva, F.A.; Bonomo, L.F.; Boasquivis, P.F.; de Paula, I.T.; Guerra, J.F.; Leal, W.M.; Silva, M.E.; Pedrosa, M.L.; Oliveira, R.P. Carqueja (Baccharis trimera) Protects against Oxidative Stress and $\beta$-Amyloid-Induced Toxicity in Caenorhabditis elegans. Oxid. Med. Cell. Longev. 2015, 740162. [CrossRef]

33. Lund, J.; Tedesco, P.; Duke, K.; Wang, J.; Kim, S.K.; Johnson, T.E. Transcriptional profile of aging in C. elegans. Curr. Biol. 2002, 12, 1566-1573. [CrossRef]

34. Walker, G.A.; White, T.M.; McColl, G.; Jenkins, N.L.; Babich, S.; Candido, E.P.; Johnson, T.E.; Lithgow, G.J. Heat shock protein accumulation is upregulated in a long-lived mutant of Caenorhabditis elegans. J. Gerontol. Ser. A 2001, 56, B281-B287. [CrossRef] [PubMed]

35. Tullet, J.M. DAF-16 target identification in C. elegans: Past, present and future. Biogerontology 2015, 16, $221-234$. [CrossRef] [PubMed]

36. Kenyon, C.; Chang, J.; Gensch, E.; Rudner, A.; Tabtiang, R.A. C. elegans mutant that lives twice as long as wild type. Nature 1993, 366, 461-464. [CrossRef]

37. Hekimi, S.; Burgess, J.; Bussière, F.; Meng, Y.; Bénard, C. Genetics of lifespan in C. elegans: Molecular diversity, physiological complexity, mechanistic simplicity. Trends Genet. 2001, 17, 712-718. [CrossRef]

38. Uno, M.; Nishida, E. Lifespan-regulating genes in C. elegans. NPJ Aging Mech. Dis. 2016, 2, 16010. [CrossRef]

39. Lin, K.; Hsin, H.; Libina, N.; Kenyon, C. Regulation of the Caenorhabditis elegans longevity protein DAF-16 by insulin/IGF-1 and germline signaling. Nat. Genet. 2001, 28, 139-145. [CrossRef]

40. Hsu, A.; Coleen, T.; Kenyon, C. Regulation of aging and age-related disease by DAF-16 and heat-shock factor. Science 2003, 300, 1142-1145. [CrossRef]

41. Tang, S.; Chen, H.; Cheng, Y.; Nasir, M.A.; Kemper, N.; Bao, E. The interactive association between heat shock factor 1 and heat shock proteins in primary myocardial cells subjected to heat stress. Int. J. Mol. Med. 2016, 37, 56-62. [CrossRef] [PubMed]

42. Mertenskötter, A.; Keshet, A.; Gerke, P.; Paul, R.J. The p38 MAPK PMK-1 shows heat-induced nuclear translocation, supports chaperone expression, and affects the heat tolerance of Caenorhabditis elegans. Cell Stress Chaperones. 2013, 18, 293-306. [CrossRef] [PubMed]

43. Pietsch, K.; Saul, N.; Swain, S.C.; Menzel, R.; Steinberg, C.E.; Stürzenbaum, S.R. Meta-Analysis of Global Transcriptomics Suggests that Conserved Genetic Pathways are Responsible for Quercetin and Tannic Acid Mediated Longevity in C. elegans. Front. Genet. 2012, 3, 48. [CrossRef] [PubMed]

44. Bonomo, L.F.; Silva, D.N.; Boasquivis, P.F.; Paiva, F.A.; Guerra, J.F.; Martins, T.A.; de Jesus-Torres, Á.G.; de Paula, I.T.; Caneschi, W.L.; Jacolot, P.; et al. Açaí (Euterpe oleracea Mart.) modulates oxidative stress resistance in Caenorhabditis elegans by direct and indirect mechanisms. PLoS ONE 2014, 9, e89933. [CrossRef] [PubMed]

(C) 2019 by the authors. Licensee MDPI, Basel, Switzerland. This article is an open access article distributed under the terms and conditions of the Creative Commons Attribution (CC BY) license (http://creativecommons.org/licenses/by/4.0/). 